\title{
Forensic examination of electronic signatures: A comparative study
}

\author{
PRIYA SHARMA \\ ORCID: 0000-0003-4986-8022 \\ Chandigarh University, Chandigarh, Punjab, India \\ MOHINDER SINGH \\ ORCID: 0000-0002-2649-1616 \\ Formerly Government Examiner of Questioned Documents \\ Central Forensic Science Laboratory, Hyderabad, India

\section{OM PraKash Jasuja} \\ ORCID: 0000-0002-2221-1242 \\ Department of Forensic Science, Chandigarh University \\ Gharua, Punjab, India
}

\begin{abstract}
The writing of names or signatures has great importance due to its use in authentication, validation, and authorization of documents. Moreover, handwritten signatures present an aura of personality and make an impression on many people. But now, with the emergence of new technologies, a variety of electronic writing media such as digital tablets and pens are being used to produce writings and signatures; and the conventional way to produce the writing using pen and paper is waning. With the changing ways of writing and signature production, the means of producing forged writing or signature are also bound to change. This has brought new challenges for handwriting examiners. In the present study, a comparative analysis of electronically captured signatures with pen-paper signatures has been performed to study the effect of changes in writing media. Signature samples were taken from the same subjects on paper and electronic
\end{abstract}


pads. The similarities and differences with respect to class and line quality features between both signatures were analysed. It was observed that despite differences between the signatures produced by the same author, it is still possible to establish the authorship of signatures in the case of electronic signatures.

Keywords: forensic science, handwriting, signature, authorship, electronic signature, digital tablet

\section{Introduction}

With the advancement in technology, the world is becoming paperless. Digital and electronic devices are in widespread use, replacing the conventional pen and paper. This advancement has brought the use of electronic signatures instead of the pen-paper signatures in various areas. Electronic signatures are the handwritten signatures produced by using electronic pads and a stylus.

Electronic signatures are mostly confused with digital signatures, but the two differ from each other. Electronic signatures are handwritten signatures captured on digital tablets; digital signatures are not only handwritten, but appended with a sort of mathematical data which is an algorithm consisting of a private key and a public key which is used for authenticating an electronic document.

In electronic signatures, the signer employs conventional methods by physically signing a document, except using traditional ink and paper. The signer writes on the surface of an electronic device with a stylus. There is a number of devices which are used for capturing electronic signatures, such as tablet PCs, Personal Digital Assistants (PDAs), and mobile telephones. Digital tablets are commonly used to capture signatures. These tablets depend on electromagnetic induction to transmit and receive information to and from the stylus. The stylus also consists of electronics for receiving and transmitting information by signals which help to locate the position of the stylus on the tablet. The use of electronic signature has simplified many tasks, for instance printing, signing, and scanning or faxing the document - one does not have to go through all the time-consuming steps to sign the documents. Other applications of electronic signatures are network access control, client identification, document workflows, electronic transaction security, contractual agree- 
ments, delivery verification, biometric security checkpoints, bank signature cards, and point-of-sale transactions. ${ }^{1}$

The signatures can be characterized by using their various features, namely class and individual ones. Class features are common to a specific group or class of writers. These features include a particular copybook form or style of letters, and the individual features are the result of diversion from the copybook form. Class characteristics have little weight in identifying a writer, as they can easily be seen in other people's writing. Individual characteristics, however, constitute the backbone of identification. If two writing samples were not prepared by the same author, then this can be established through a significant difference in either individual or class characteristics. ${ }^{2}$ The fundamental or significant differences are those beyond the range of natural variations. They cannot be accounted for by external and internal factors such as age, illness, mental state, the writing instrument, and writing support. ${ }^{3}$ Hilton states that "hesitation, unnatural pen lifts, patching, tremor, the uncertainty of movement as portrayed by abrupt changes in the direction of the line, and a stilted, drawn quality devoid of free, normal writing movements combine to reveal the true nature of a forgery." 4

The way of writing or signing depends on the combined effect of both external and internal factors, which cause variations in handwriting or signatures. Variation is an essential part of genuine handwriting and no two samples of writing made by one and the same person are identical in every detail. The extent of natural variation is different for every writer, so it is an important element in the identification of handwriting. In some cases the variation occurs only in few details of the writing, but in others the formation of letters and words may differ to a great extent. The variation is due to not only the lack of machine-like precision in human activities, but also to external factors such as writing position, the type of writing instrument used, and the amount of care given to the writing.

1 H.H. Harralson, Developments in handwriting and signature identification in the digital age, UK 2013.

2 O. Hilton, The scientific examination of questioned document, New York 1982.

3 R.A. Huber, A.M. Headrick, Handwriting identification: Facts and fundamentals, Boca Raton, FL 1999.

4 O. Hilton, op. cit., p. 185. 
The variation may also be influenced by the physical or mental condition of the writer: fatigue, intoxication, drug use, illness, and nervousness. The degree and intensity of these conditions affect the extent of variation in the writing. The variation does not affect the identification of handwriting, but indicates its genuineness. Handwriting is influenced by the nature of the writing instrument and the writing surface. It is a fact that handwriting is a product of neuromuscular coordination, so irrespective of the writing instrument (i.e. electronic pad and stylus), the brain which controls the movement of the hand remains the same. Therefore, the structure of handwriting remains unaltered and consistent, and it is only the general appearance of the writing which is affected by the nature of the writing instrument. We may encounter many cases in which we have to compare the questioned electronic signatures with pen-paper signatures or vice versa.

The present work is a comparative study of the electronic signature with conventional pen-paper signatures. A signature captured on an electronic pad was compared with a signature handwritten on paper with a ballpoint pen. The similarity and differences between an electronic signature and a pen-paper signature have been studied.

Galen and Gemmert ${ }^{5}$ examined the differences between natural and simulated handwriting on the basis of spatial and dynamic variables using a digitizer tablet. Wright ${ }^{6}$ discussed the use of electronic signatures for the authentication of legal documents. Plamondon and Srihari ${ }^{7}$ described the automatic handwriting recognition models and discussed the algorithms for on-line (digitally captured) and the off-line (scanned images) handwriting recognition. Bharvada ${ }^{8}$ reviewed the various types of electronic signatures and their advantages. Mason illustrated the evi-

5 G. Galen, A. van Gemmert, "Kinematic and dynamic features of forging another person's handwriting", Journal of Forensic Document Examination 9, 1996, pp. 1-25.

6 B. Wright, "Making electronic signatures a reality", Computer Law \& Security Review 15, 199, no. 6, pp. 401-402.

7 R. Plamondon, S.N. Srihari, "On-line and off-line handwriting recognition: A comprehensive survey", IEEE Transactions on Pattern Analysis and Machine Intelligence 22, 2000, pp. 63-84.

8 K. Bharvada, "Electronic signatures, biometrics and PKI in the UK", International Review of Law, Computers \& Technology 16, 2002, pp. 265-275. 
dential issues related to electronic signatures ${ }^{9}$ and presented a comparison of the risks between the use of electronic signature and manuscript signatures. ${ }^{10}$ Richiardi et al. ${ }^{11}$ examined 39 local (based on single data point) and 46 global (based on the entire signature unit) features for online systems to find out the most efficient and most discriminating power for signature verification. Tariq et al. ${ }^{12}$ evaluated the strong and weak features in an online signature verification system.

Harralson et al. ${ }^{13}$ examined the temporal (dynamic) and spatial (static) differences between online and offline signatures. The signature samples in three different conditions, that is, on paper using a ballpoint pen, on Wacom Intuos 3 tablet, and using a mouse, were collected. He observed the difference in features such as a change in size, simplification of signatures, slow movements, and a change in the spacing of signatures. Harralson ${ }^{14}$ stated that the electronic signatures are digitized and the this process leads to some common differences, for instance in the shading of ink traces, feathered beginning and ending strokes converted into blunt strokes. Smooth air strokes and lifts in the signature appeared to be cut off or blunt after digitization. These differences may lead to erroneous opinions when comparing electronic signatures captured on digital tablets to pen-paper signatures.

9 S. Mason, "Electronic signatures - Evidence: The evidential issues relating to electronic signatures", part 1 and part 2, Computer Law \& Security Report 18, 2002, no. 3 , pp. $175-180$, no. 4 , pp. 241-248.

10 S. Mason, "A comparison of the risks between the use of manuscript and electronic signatures", Amicus Curiae 50, 2003, pp. 11-13.

11 J. Richiardi, H. Ketabdar, A. Drygajlo, "Local and global feature selection for online signature verification", International conference on document analysis and recognition, 29 August-1 September 2005, pp. 625-629.

12 S. Tariq, S. Sarwar, W. Hussain, "Classification of features into strong and weak features for an intelligent online signature verification system", Proceedings of the 1st International Workshop on Automated Forensic Handwriting Analysis (AFHA), 17-18 September 2011, Bejing.

13 H.H. Harralson, H.L. Teulings, S.L. Miller, "Temporal and spatial differences between online and offline signatures", 15th International Graphonomics Society Conference, 12-15 June 2011, pp. 34-37.

14 H.H. Harralson, op. cit. 
Kaźmierczyk and Turner ${ }^{15}$ differentiated between the electronic signatures and handwritten signatures. They also observed changes in features such as dimension, loss or addition of details, blunt strokes instead of feathered strokes, expansion, pen lifts, simplification, and abrupt change in direction. It was concluded that writers alter their signature in order to meet the requirements of the software.

Mohammed et al. ${ }^{16}$ observed the dynamic features (duration, size, velocity, jerk, and pen pressure) between genuine and simulated signatures with the effect of stylization. Stroke duration, velocity, and pen pressure were found to be inconsistent between genuine and simulated signatures. This indicated that the style of the simulator's own signature and the style of the simulated signature can impact the characteristics of handwriting movements.

All these studies were about differentiating between genuine and forged signature captured on electronic pads based on their dynamic features such as speed, pressure, duration, etc.

But before studying about differences between forged and genuine writings on electronic media, one should be aware of the differences that occur within the genuine signatures depending on whether they were written on paper or on an electronic device. Therefore, in the present study, an attempt is made to determine if due to a change in the medium of writing fundamental differences are affected or if they remain within the range of natural variations.

\section{Material and methods}

The aim of this study was to identify the differences, if there are any, among the two sets of signatures written by the same individual on a digital writing pad with the help of a stylus and on paper with a conventional writing instrument (the ball pen).

15 Z.Kaźmierczyk,I. Turner, “Isyourelectronicsignaturereallyyours?”,https://www.academia.edu/6630002/Is_your_electronic_signature_really_yours (accessed: 18.11.2016).

16 L. Mohammed et al., "Dynamic characteristics of signatures: Effects of writer style on genuine and simulated signatures", Journal of Forensic Sciences 60, 2015, no. 1, pp. 89-94. 


\section{Selection of the subjects}

The samples for the present research work were collected from fifty subjects, all of whom were skilled writers, well-educated (with graduation as a minimum qualification), and users of online shopping websites. The subjects were randomly selected. Nineteen of them were fully familiar with digital tablets and had used them or cell phones for delivery verifications. Informed consent was obtained along with the subjects' names, ages, and qualifications. Additionally, it was recorded whether the subjects had used these devices earlier, including for signing purposes.

\section{Writing conditions}

Since usually signatures are made in a standing position, for instance during delivery verifications, in shopping stores and banks, the subjects were requested to sign in that very position to simulate the actual position of writing in both the cases, that is, electronic devices as well as paper.

\section{Writing instruments}

The signatures were collected on white A4 sheets using a blue ballpoint pen and on a digitalizing tablet - Bamboo $^{\text {TM }}$ Pad, a USB model by Wacom Company - using a stylus. The general specifications of the device are as follows:

- physical size: $(\mathrm{W} \times \mathrm{D} \times \mathrm{H}) 141.4 \times 166.5 \times 4.5 \mathrm{~mm}$;

- pen technology: electromagnetic resonance technology;

- pen active area: $(\mathrm{W} \times \mathrm{D}) 107 \times 67 \mathrm{~mm}$;

- readable height: $16 \mathrm{~mm}$;

- communication interface: USB;

- operation: the blue LED lights up after powering the units on. Brighter blue when touch is used. Amber when the pen is used. The pad is pressure sensitive when used with a stylus. It only produces writing when the stylus is touching the surface with a certain pressure and an amber light turns on. 


\section{Sample collection method}

The Bamboo ${ }^{\mathrm{TM}}$ pad was connected to a PC using its USB. Then the signatures were captured in a computer graphics application Microsoft Paint (MS Paint) and the image was saved in TIFF format. Unlike other formats, TIFF has the ability to store image data in a lossless compression and makes a TIFF file in a useful image archive. A TIFF file can be edited and re-saved without losing image quality. The subjects were allowed to look at the desktop while signing for proper device positioning on the tablet surface. Four signature samples were collected both on the digital tablet and on paper to find the natural variation in the subjects' writing. All samples from one subject were within their range of variation. So out of four samples one signature was randomly chosen and used for detailed examination (in results).

\section{Sample analysis}

The pen-paper signatures were analyzed using a magnifying glass and scale. The electronic signatures were analyzed in MS Paint by magnification, ruler, and gridlines available in it. The features with their respective significance mentioned in previous studies and literature which were selected to compare the pen-paper signatures and electronic signatures include:

1. dimensions: vertical and horizontal,

2. spacing,

3. alignment,

4. arrangement,

5. initial and terminal strokes,

6. connecting strokes,

7. pen lifts,

8. diacritics,

9. embellishments,

10. tremors,

11. simplification,

12. forms and formation. 


\section{Results and discussion}

The differences and similarities were observed in the pen-paper signature and electronic signature of 50 subjects. The percentage of the observed feature was calculated.

\subsection{Dimensions: vertical and horizontal}

A comparison between the horizontal dimension (i.e. length of the signature) and vertical dimension (i.e. height of lowercase and uppercase letters) showed that all the subjects increased the horizontal dimension - that is, the measured parallel to the baseline using scale from the first letter to the last letter of the signature - and vertical dimension of signature - that is, the height of uppercase and lowercase letter on digital tablet were also measured (Figure $1 \mathrm{a}$ and $1 \mathrm{~b}$, Figure $2 \mathrm{a}$ and $2 \mathrm{~b}$ ). Then the total percentage increase in the length of the signature the height of uppercase letters, and height of lowercase letters, were calculated.

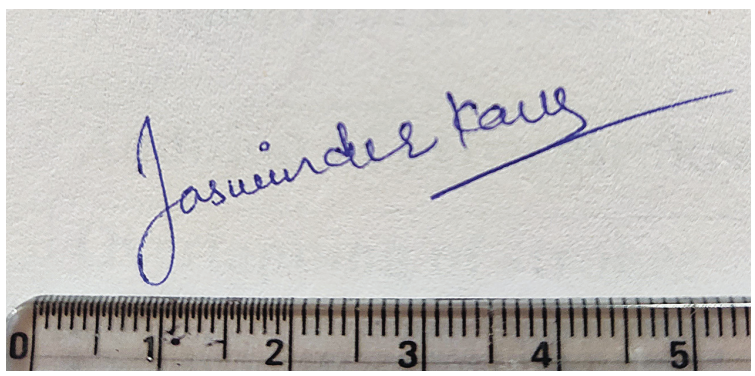

Figure 1a. The horizontal dimension of pen-paper signature with a ruler in $\mathrm{cm}$

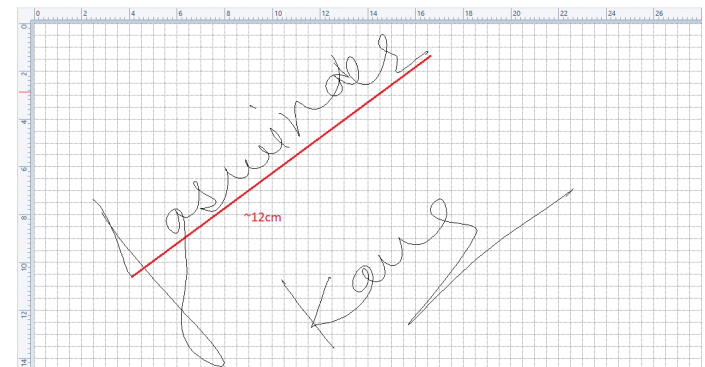

Figure $1 \mathrm{~b}$. The change in horizontal dimension of electronic signature 


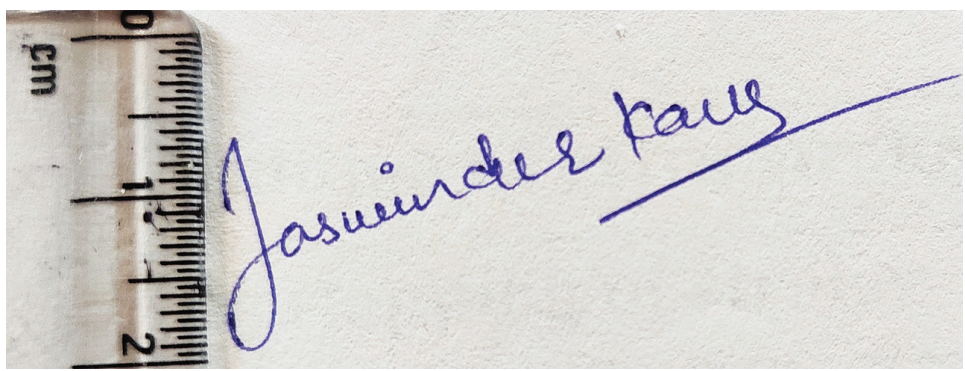

Figure 2a. The vertical dimensions of pen-paper signature and electronic signature

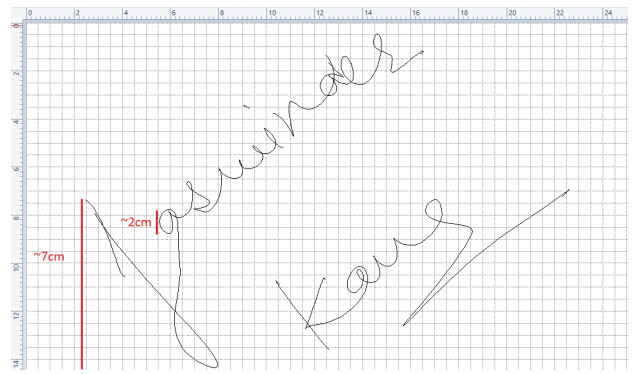

Figure $2 \mathrm{~b}$. The change in vertical dimension

It is clear from Table 1a-c that the increase in the signature size with respect to the length and height remains almost constant, indicating that the writer's neuromuscular impulse remains unchanged irrespective of the writing surface. The height and width ratios also remain the same in both cases, indicating that a skilled writer's writing habit cannot be changed depending on the writing surface. Jasuja et al. ${ }^{17}$ reported similar findings in their study of wall writings - the writing size may increase with the change in writing surface and instrument, but the height and width ratios remain almost the same. These observations make it evident that the same method of examination can be applied to examine and compare the electronic signature and pen-paper signatures.

17 O.P. Jasuja et al., "Spray paint writings on vertical surfaces executed by spray paint cans: A preliminary forensic study", Z Zagadnień Nauk Sąowych (Problems of Forensic Sciences) 98, 2014. 
Table 1a. Length of the signature

\begin{tabular}{|c|c|c|}
\hline $\begin{array}{c}\text { Average length } \\
\text { of the pen-paper signature } \\
\text { (initial average value) }\end{array}$ & $\begin{array}{c}\text { Average length } \\
\text { of the electronic signature } \\
\text { (final average value) }\end{array}$ & $\begin{array}{c}\text { Total percentage increase } \\
\text { in length of the signature }\end{array}$ \\
\hline $2.584 \mathrm{~cm}$ & $13.104 \mathrm{~cm}$ & $\begin{array}{c}(13.104-2.584) / 2.584 \\
\times 100=407.12 \%\end{array}$ \\
\hline
\end{tabular}

Table 1b. Height of uppercase letters

\begin{tabular}{|c|c|c|}
\hline $\begin{array}{c}\text { Average height of upper- } \\
\text { case letters in the pen- } \\
\text { paper signature } \\
\text { (initial average value) }\end{array}$ & $\begin{array}{c}\text { Average height of upper- } \\
\text { case letters in the elec- } \\
\text { tronic signature } \\
\text { (final average value) }\end{array}$ & $\begin{array}{c}\text { Total percentage increase } \\
\text { in height of uppercase } \\
\text { letters in the signature }\end{array}$ \\
\hline $0.974 \mathrm{~cm}$ & $4.548 \mathrm{~cm}$ & $\begin{array}{c}(4.584-0.974) / 0.974 \\
\times 100=366.94 \%\end{array}$ \\
\hline
\end{tabular}

Table 1c. Height of lowercase letter

\begin{tabular}{|c|c|c|}
\hline $\begin{array}{c}\text { Average height } \\
\text { of the lowercase letter } \\
\text { of pen-paper signature } \\
\text { (initial average value) }\end{array}$ & $\begin{array}{c}\text { Average height } \\
\text { of the lowercase letter } \\
\text { of electronic signature } \\
\text { (final average value) }\end{array}$ & $\begin{array}{c}\text { Total percentage increase } \\
\text { of lowercase letter } \\
\text { of the signature }\end{array}$ \\
\hline $0.24 \mathrm{~cm}$ & $1.232 \mathrm{~cm}$ & $\begin{array}{c}(1.232-0.24) / 0.24 \\
\times 100=413.33 \%\end{array}$ \\
\hline
\end{tabular}

The reason for enlargement may be the device itself - during the present study an experiment was conducted in which $1 \mathrm{~cm}$ line was drawn on paper and the paper was put over the surface of a pad, which was sensitive enough to locate the stylus while the paper was put over it. The stylus was moved over the pre-measured line and the line was drawn in "paint." The approximate length was found to be $3 \mathrm{~cm}$.

Kaźmierczyk and Turner ${ }^{18}$ also conducted an experiment in which a $1 \mathrm{~cm}$ long line was drawn on a tablet. It was observed that the line which appeared on a screen was $1.8 \mathrm{~cm}$ long, which means that most signatures written using this device might become bigger automatically.

18 Z. Kaźmierczyk, I. Turner, op. cit. 
The study by Harralson et al. ${ }^{19}$ showed an increase in the size of electronic signatures in $75 \%$ of the writers, and a decrease in size in $25 \%$. In the present study, no decrease in size was observed.

\subsection{Spacing between letters}

The change in spacing between letters was observed in electronic signatures (Figure 3a and Figure 3b).

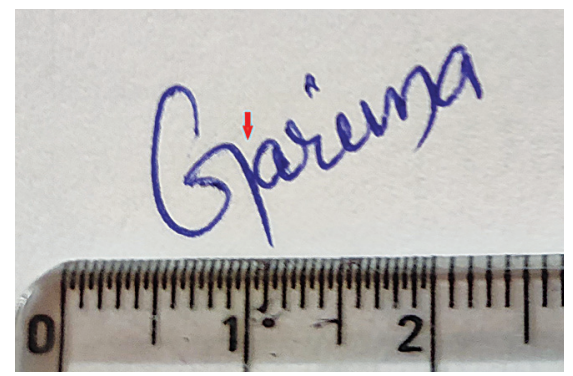

Figure 3a. The narrow spacing between letters in pen-paper signature

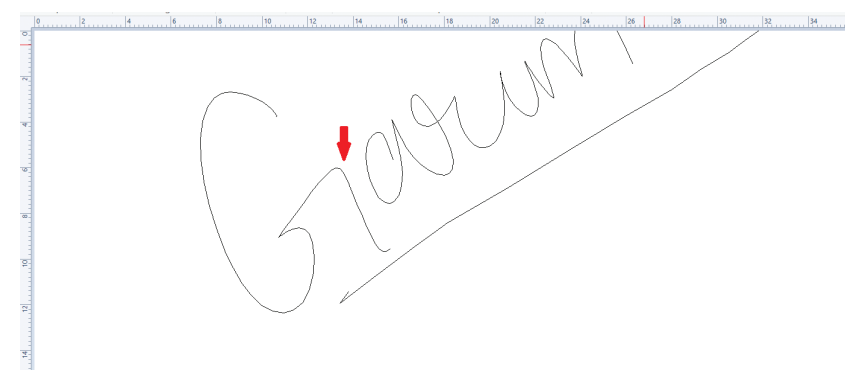

Figure $3 \mathrm{~b}$. The increase in spacing in electronic signature

There were 9 subjects who changed the spacing from narrow to wide, 10 subjects from uniform to wide, 16 subjects from irregular to wide, 5 subjects from wide to wider, 5 subjects from narrow to irregular, 2 subjects from uniform to irregular, and 3 subjects did not change the uniform spacing.

19 H.H. Harralson, H.L. Teulings, S.L. Miller, op. cit. 
In 6 samples, the spacing increased so much that the subjects ran out of the available space to complete the signature. In 4 samples the spacing was irregular and decreased only between a few letters, leading to the overlapping of letters.

The wide spacing between letters was observed in the writings of most subjects. This could be due to the increase in the signature's dimensions. The overlapping could be caused by the lack of visual feedback on the tablet surface.

\subsection{Spacing between words}

People generally develop their signature as per their choice; once it is developed, it remains the same. Some people may write their signature as a single pen operation, while many may have pen lifts. When a writer includes their second name (surname) in their signature, then most likely they have to lift the pen and then write the second name. In the present study, the surname and first name were present in 34 samples of penpaper signatures, while in 16 samples no surname was present.

The change in spacing between first name and surname in 34 subjects was observed (Figure 4a, Figure 4b, Figure 5a, and Figure 5b). The increase in spacing was observed in 19 samples, decreased in 3 samples, and no change in 12 samples.

The increase in spacing could be due to the change in dimension, the decrease - to the lack of visual feedback. It also may be the case that as the dimension increased, the spacing was decreased to adjust the signature in the limited space.

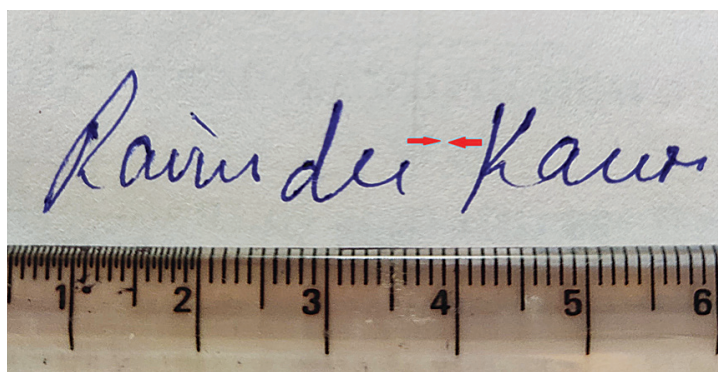

Figure 4a. The spacing between words in pen-paper signature 


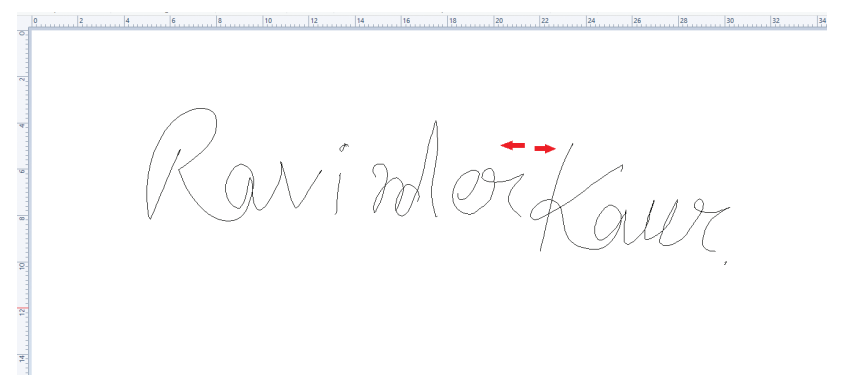

Figure $4 \mathrm{~b}$. The decreased spacing between words in electronic signature

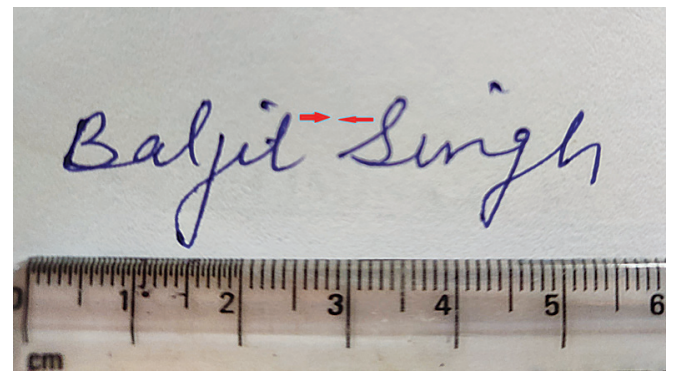

Figure 5a. The space between words in pen-paper signature

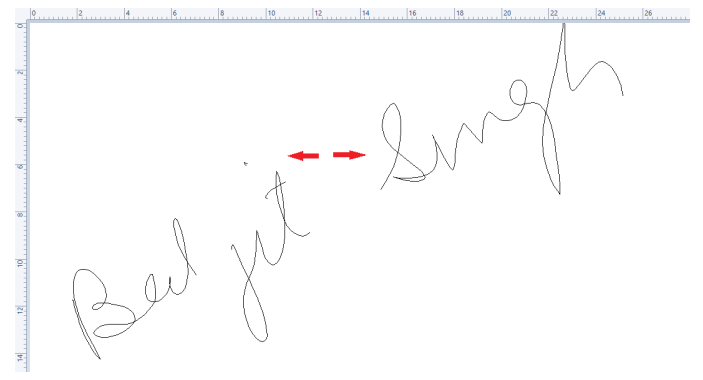

Figure $5 \mathrm{~b}$. The increased spacing between words in electronic signature 


\subsection{Alignment}

The most common way used by criminals to alter the appearance of writing is by changing alignment and slant. These changes can be identified easily in a long passage of writing, but not in the case of signatures - only very small writing is available and it can mislead the forensic handwriting examiners. In the case of writing with a pen on paper and writings on a digital tablet, a change in alignment was observed. A tendency to shift towards ascending was observed - in the present study 7 subjects changed the alignment from straight to ascending, 9 changed the alignment from irregular to ascending, and 3 from arched to ascending. In 10 samples the alignment was ascending and remained so, but to a higher degree (Figure 6a and Figure 6b).

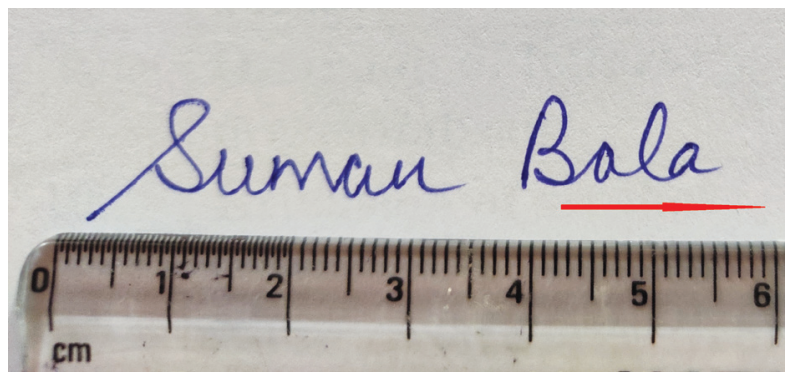

Figure 6a. The straight alignment in pen-paper signature

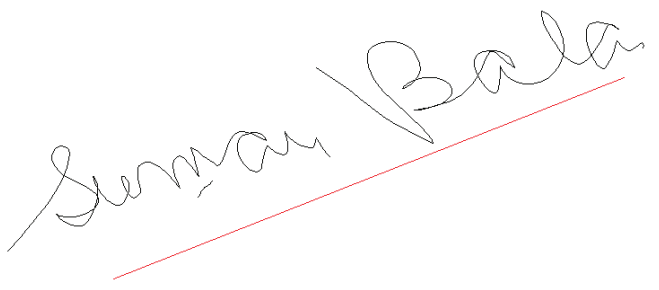

Figure $6 \mathrm{~b}$. The ascending alignment in electronic signature

Most of the subjects signed in an ascending way. This could be due to the limited area to sign on the tablet. So, to complete the signature in the available area, subjects may have changed the alignment. No remarkable change in alignment was observed in 21 samples. 


\subsection{Arrangement}

Since the writing samples were in the form of signatures in the present study, the arrangement was not found to be affected. There was no difference in the arrangement of signatures written conventionally and on a digital pad. There were 39 cases where there was no change observed, while 11 subjects changed the arrangement from one line into two lines (Figure 7a and Fig 7b). The reason for this might be that the increase in size and spacing of the signature caused the writer to move half of the signature into the second line. The other explanation may be the small area of the tablet due to which the subjects might have been unable to complete the signature in one line. Finally, it may be a case of first-timers using the digital pad for signatures.

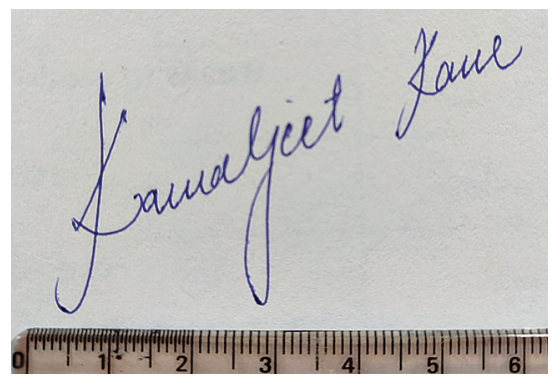

Figure $7 \mathrm{a}$. The arrangement of pen-paper signature

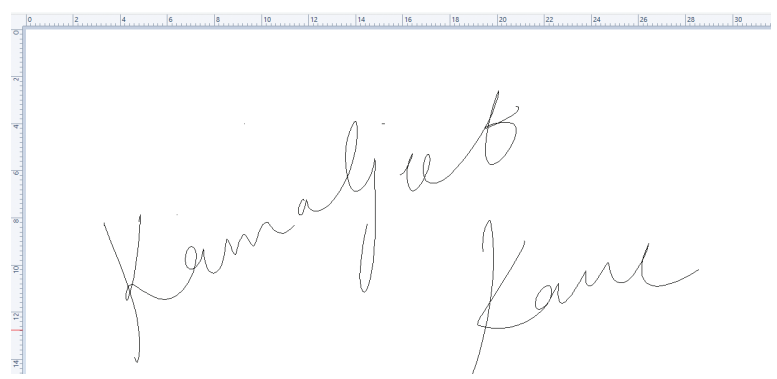

Figure $7 \mathrm{~b}$. The changes in arrangement in electronic signature 


\subsection{Initial and terminal strokes}

One of the most important features of one's writing are the flying or tapered initial and terminal strokes. Due to high skill and fluency, the writing will be executed with more speed and less pressure. In the present study, all the writers were skilled and it was supposed that their writings - particularly signatures - were written with more speed than a typical text, thus making it a very important feature for studying the difference between writings created using various media. The present study noted changes in writing strokes with respect to initial and terminal strokes. All these changes could be classified into the following categories: 1 . hooks present or not, 2. stroke eyelet modified into retrace, 3 . length of the terminal stroke increased or decreased. It was observed that in 9 electronic signature samples hooks were absent from the initial strokes (Figure 8a and Figure $8 \mathrm{~b}$ ). The absence of initial or terminal strokes with hooks could be due to the improper positioning of the stylus over the tablet surface, which may have led to the omission of strokes.

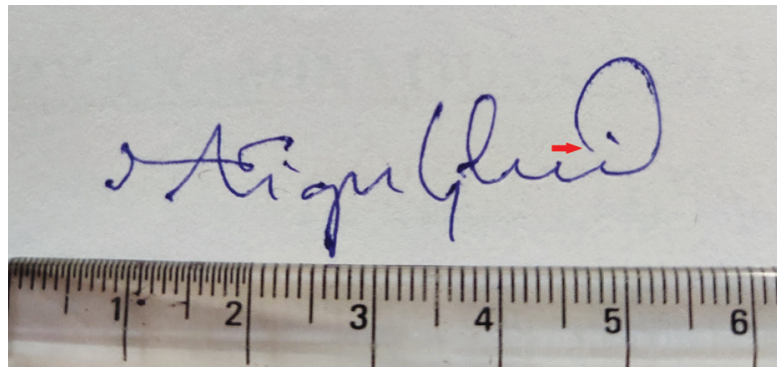

Figure $8 \mathrm{a}$. The initial stroke with tapering end and terminal stroke at letter ' $r$ ' in pen-paper signature

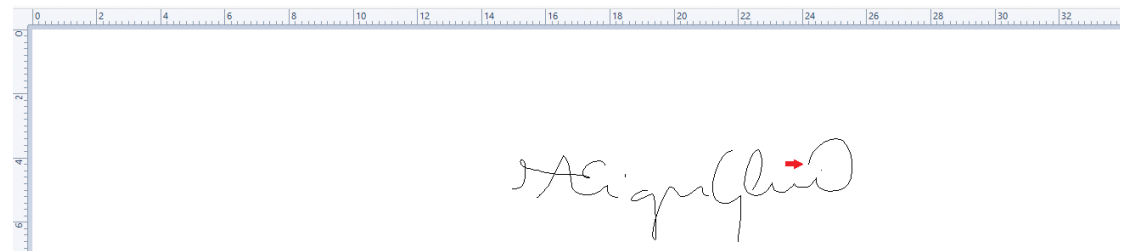

Figure $8 b$. The absence of initial stroke at letter ' $p$ ' and extension of terminal stroke at letter ' $r$ ' 
In 7 conventional writing samples retracing was modified into eyelets. The modification in the forms of the initial stroke (eyelets instead of retrace) and the terminal stroke may be due to a lack of visual feedback on the tablet surface. In 18 electronic signature samples the length of terminal strokes was increased. The prolonged touching of the stylus over the tablet surface maybe led to the extension of strokes. In all the electronic signatures tapering ends were converted into blunt endings (Figure $9 \mathrm{a}$ and Figure $9 \mathrm{~b}$ ). Harralson ${ }^{20}$ mentioned that there is no grayscale available in digitized signatures, so all tapered endings were converted into blunts strokes.

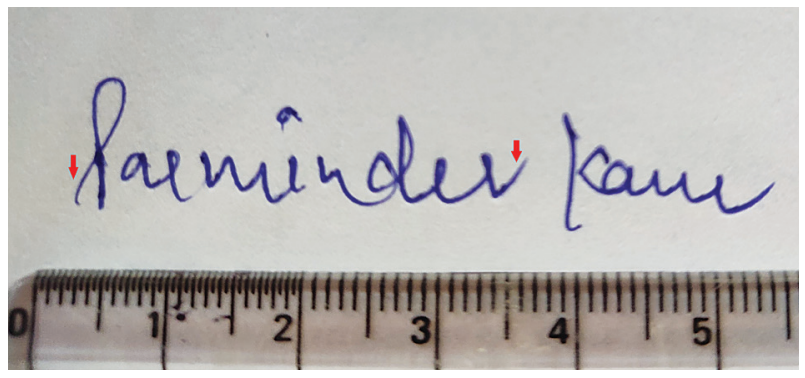

Figure 9a. The tapered ending in pen-paper signature

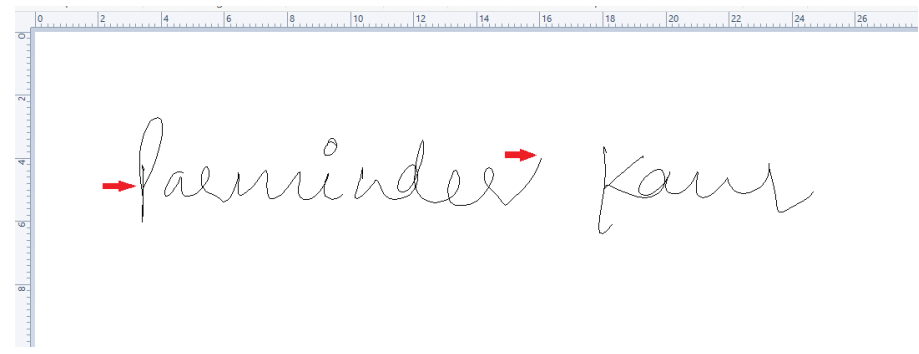

Figure $9 \mathrm{~b}$. The blunt ending in electronic signature

20 H.H. Harralson, op. cit. 


\subsection{Connections}

Skilled writers are supposed to write in cursive form and therefore most of the letters in one word are connected with each other. Letters of a word are connected with the connecting strokes which have a characteristic feature with respect to their form and formation. The present study aimed to observe if the form and formation of these strokes were similar in both signature sets. The observations were made in accordance with the following questions: were the connecting strokes are present in both signature sets? If so, is the placing of these strokes also similar? Was there any addition or subtraction in the connecting strokes? What was the form/formation of the connecting strokes? Connecting strokes were observed in 44 samples of pen-paper signatures, and they were absent in the other 6 samples. In 9 samples some connecting strokes were added which were absent in pen-paper signatures (Figure 10a and Figure 10b). The addition of connecting strokes in unusual places could be caused by the contact of the stylus with the surface if the subjects did not raise the stylus. The connecting strokes in 34 samples were in the retraced form and were modified into the eyelets. The surface was not as smooth as in pen-paper signatures, so retracing was rarely present in electronic signatures. The length of connected strokes was increased in signatures of 37 subjects (Figure 11a and Figure 11b). Spacing was also increased - the reason could be the lack of visual feedback.

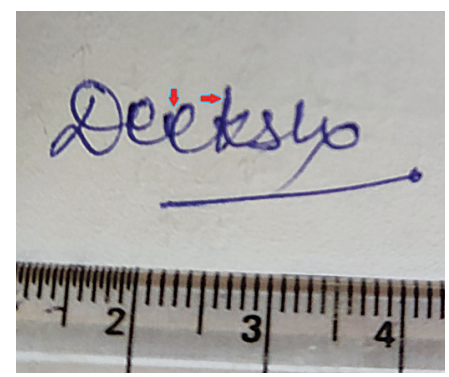

Figure 10a. The retraced connecting strokes in pen-paper signature 


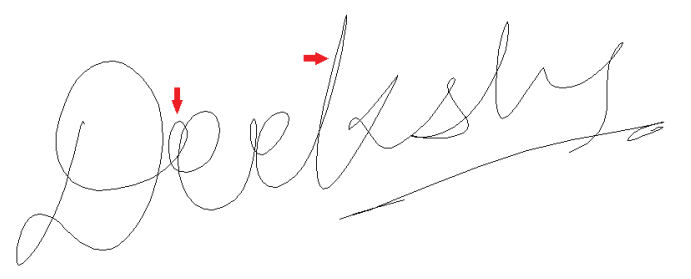

Figure 10b. The eyelets formed in electronic signature

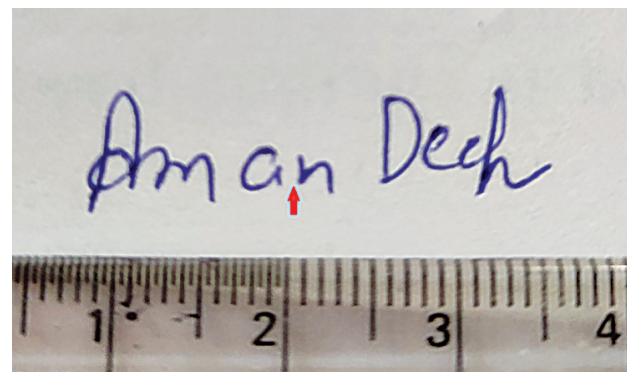

Figure 11a. The absence of connecting stroke and length of connecting stroke in pen paper signature

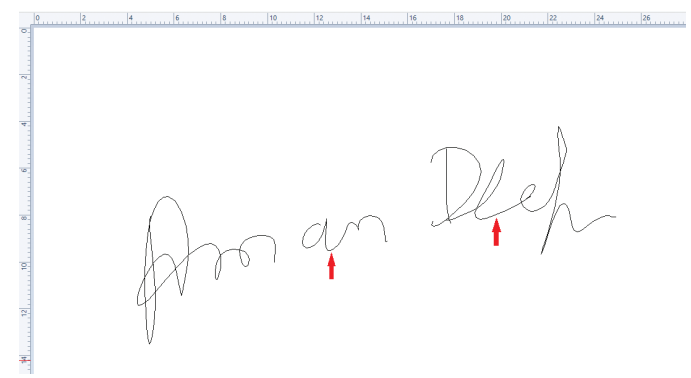

Figure 11b. The addition of connecting strokes and extension of connecting strokes in electronic signature 


\subsection{Pen lifts}

In the present study, pen lifts indicated a very important point while comparing signatures on paper and on the digital pad. It seemed obvious to presume that whatever pen lifts were present in pen-paper signatures, the same should also be present in digital pad signatures. But it was not so - in 21 digital pad signature samples pen lifts were present in unusual places. Most of such pen lifts led to the omission of strokes, as is evident from Figure 12a and Figure 12b. However, in 19 samples there was an absence of pen lifts in electronic signatures while they were present in the pen-paper signature sample provided by the same subject. As evident from Figure 13a. and Figure 13b, the absence of pen lifts leads to the addition of extra strokes. It is thought that these changes may be due to improper positioning of the stylus over the tablet surface, but it cannot be said with certainty.

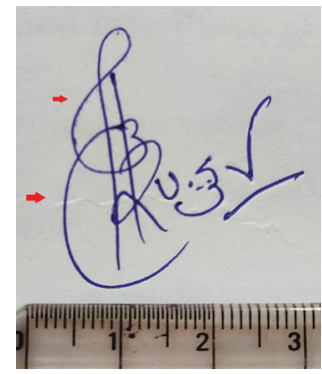

Figure $12 \mathrm{a}$. The pen-paper signature

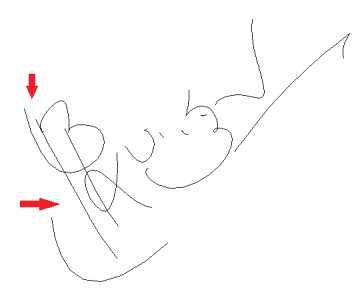

Figure 12b. The omission of strokes due to pen lifts in electronic signature 


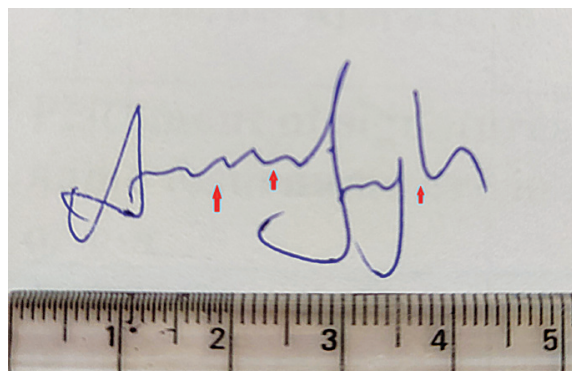

Figure 13a. The pen lifts in pen-paper signature

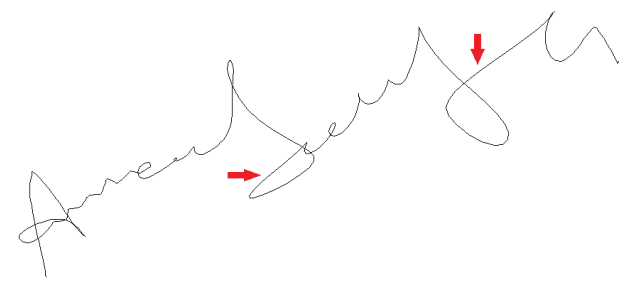

Figure 13b. The absence of pen lifts in electronic signature

\subsection{Diacritics}

In the present study, ' $i$ ' dots, ' $j$ ' dots, and the crossbar of ' $t$ ' were considered for the comparison of two sets of signatures from different media. The changes were observed but not significant, and the increase or decrease in the positioning of the dots or the length of the crossbar can be considered a result of natural variations. Figures 14-15 indicate changes/ variations in diacritic marks in these two sets of signatures. In all samples the ' $i$ ' dot was observed in 24 cases, and out of these 24 the shape of the ' $i$ ' dot was modified in 13 samples, while in 11 samples it was omitted. At the same time, 10 subjects changed the position of the dot. In case of the ' $t$ ' crossbar, out of 16 samples the crossbar was completely omitted in 2, while 6 subjects extended its length. The prolonged touching of the stylus may have caused the extension of the ' $t$ ' cross. 


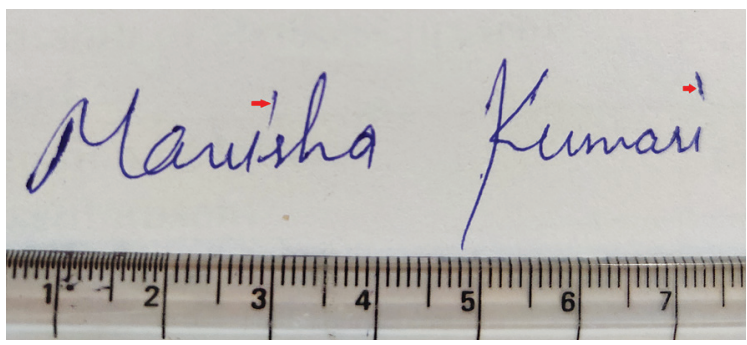

Figure 14a. The pen-paper signature

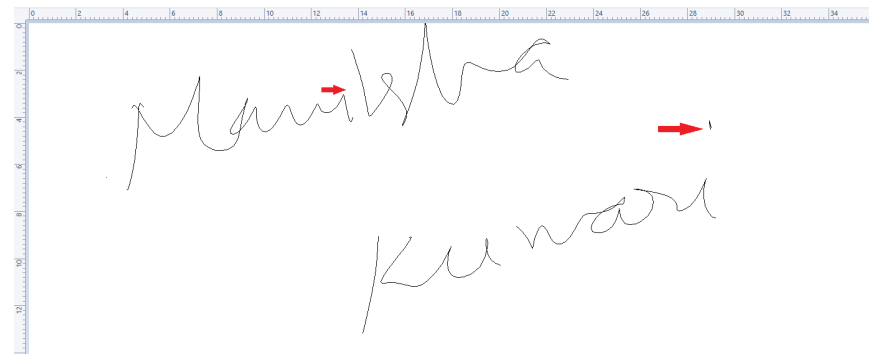

Figure 14b. The omission of ' $\mathrm{i}$ ' dot and change in shape of ' $\mathrm{i}$ ' dot in electronic signature

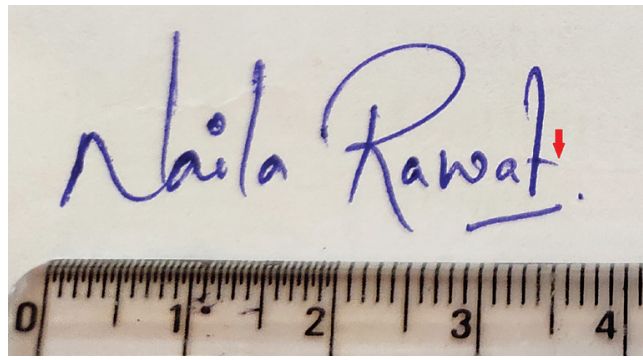

Figure 15a. The length and position of t-cross in pen-paper signature

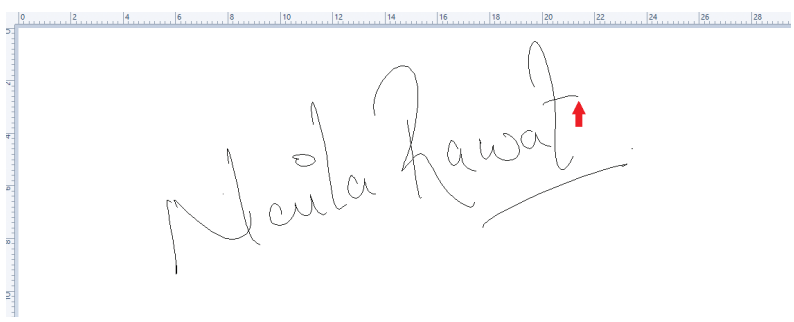

Figure $15 \mathrm{~b}$. The change in length and position of t-cross in electronic signature

Nowa Kodyfikacja Prawa Karnego 59, 2021

(C) for this edition by CNS 


\subsection{Embellishments}

Embellishments are not necessarily present in everyone's writing, but when present, they may indicate certain individuality as well as a sort of idiosyncrasy. A person who adds embellishments in the writing will certainly keep those come what may. Therefore, in the present study, it was an important observation if embellishments did vary with the change of the media of writing, and if so, in what way. Embellishments were observed in the writing with respect to their presence or absence, their position, they were modified, and if so, whether there were some additions or omissions.

In total, embellishments were present in signatures of 27 subjects. Embellished strokes were omitted in 9 samples while writing on the digital pad, and modified in 11 samples. No change in embellishments was observed in 7 samples. An addition of embellishments was observed in 11 samples, 2 subjects completely omitted the rubrics, and 12 subjects modified them. Furthermore, 2 subjects added the rubrics in the electronic signature while they were absent in pen-paper signatures (Figure 16a-b and Figure $17 \mathrm{a}-\mathrm{b})$. All these observations indicate an unorganized representation of this feature because of natural variation in the signatures. The writer may be more conscious during the process of forming their signature on the tablet than when signing on paper. So, if there were rubrics added or ornamentations modified in the electronic signature, this might be due to the lack of speed and fluency present in the pen-paper signatures.

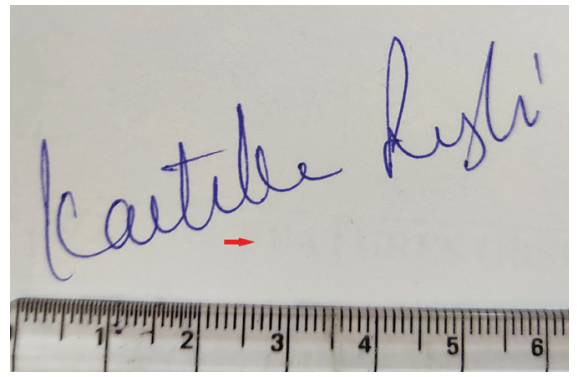

Figure 16a. The absence of rubric in pen-paper signature 


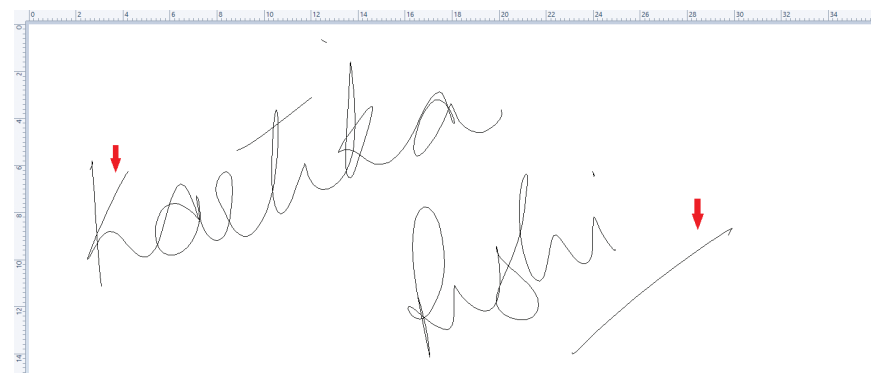

Figure 16b. The presence of rubric and addition of embellished letter ' $\mathrm{k}$ ' in electronic signature

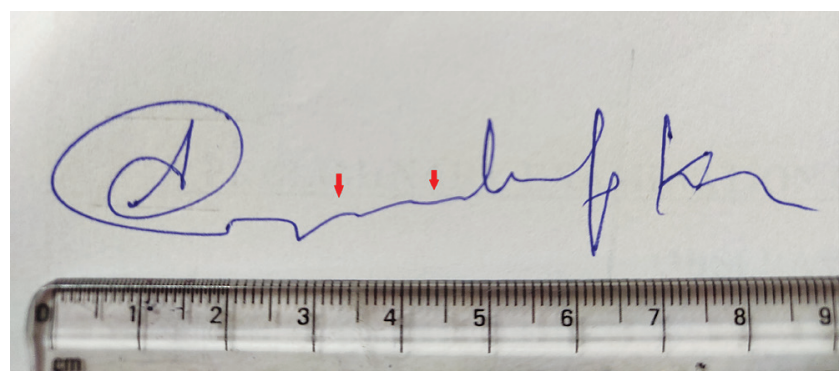

Figure 17a. The embellishment of letter ' $a$ ' in pen-paper signature

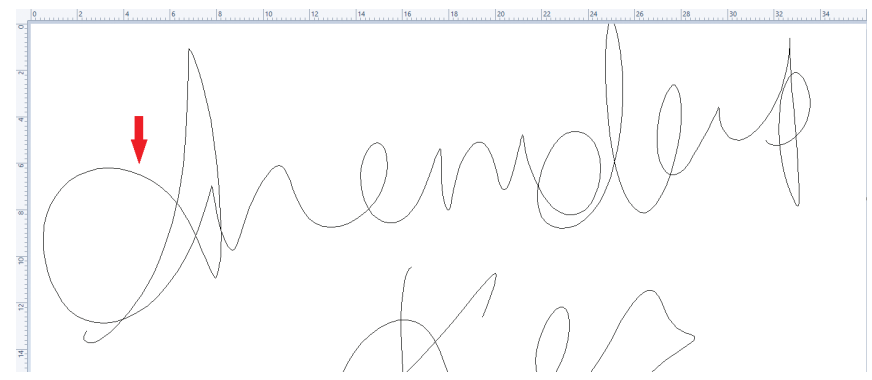

Figure $17 \mathrm{~b}$. The modification in embellishment in electronic signature 


\subsection{Tremors}

Tremors in the handwriting are supposed to be the result of two factors: they are present either due to neuromuscular incoordination or to some kind of forgery. Therefore, it was unusual to observe that tremors were present in one's handwriting when written on the digital pad, while in the normal writing on paper no tremors were present. The strokes of the 36 samples of electronic signature were tremulous (Figure 18a-b). The awkwardness of signing on a digital tablet may cause the tremor in strokes. The other possible reason could be the lack of smoothness characteristic of paper on the tablet surface, which leads to a tremor in strokes.

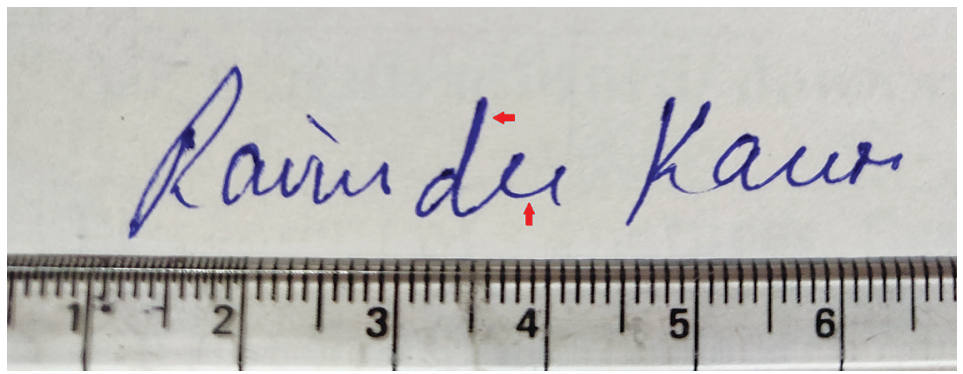

Figure 18a. The clear-cut strokes of pen-paper signature

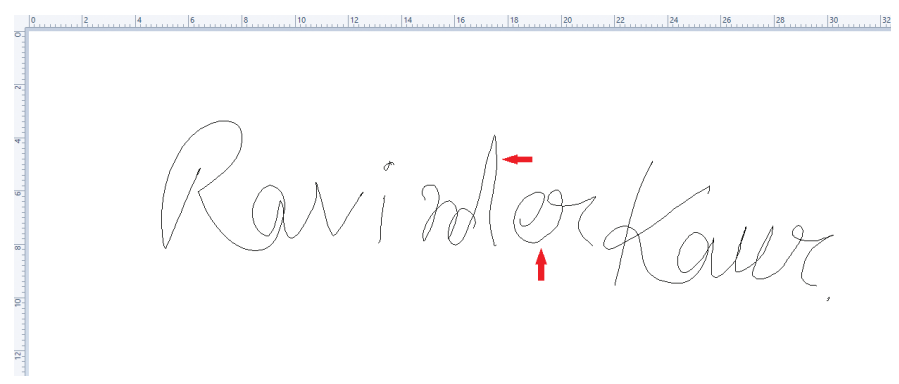

Figure 18b. Tremulous stroke in electronic signature 


\subsection{Simplification}

Simplification of the strokes in handwriting or signatures may be caused by the tendency of the writer to write quickly because of overburdening with the task to produce more writing in a limited time. But in the present study, the writers were provided with enough time and no time limit. However, the occurrence of simplification was not very frequent - it was found only in 9 samples (Figure 19a-b and 20a-b). The possible reason, as mentioned above, may be the writer's casualness and the significance of the writing.

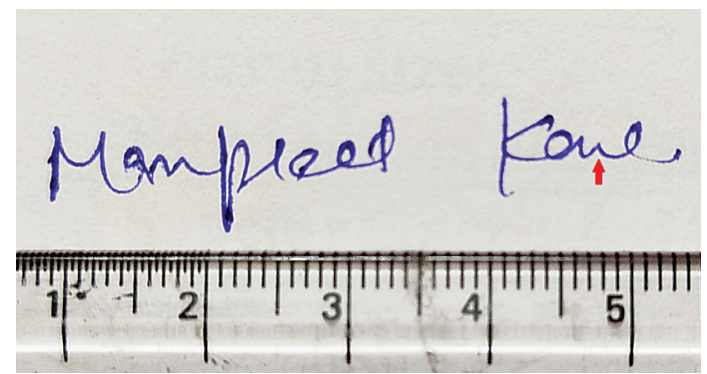

Figure 19a. The pen-paper signature

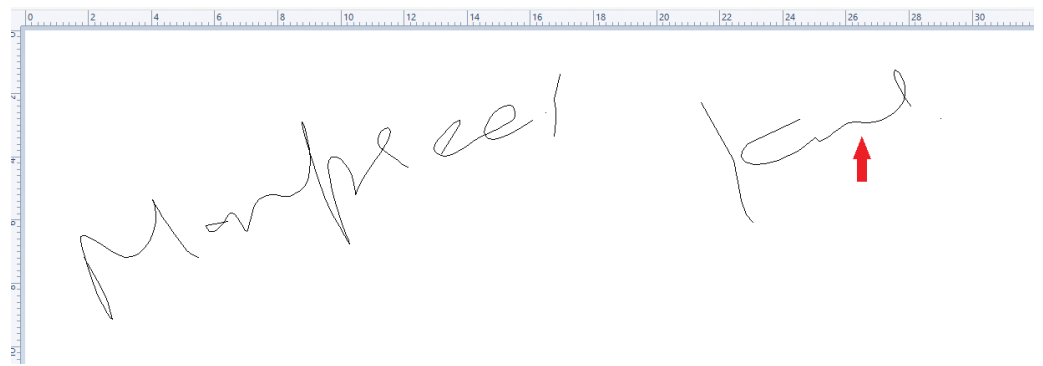

Figure 19b. The simplification of letters ' $a$ ' and ' $u$ ' in electronic signature 


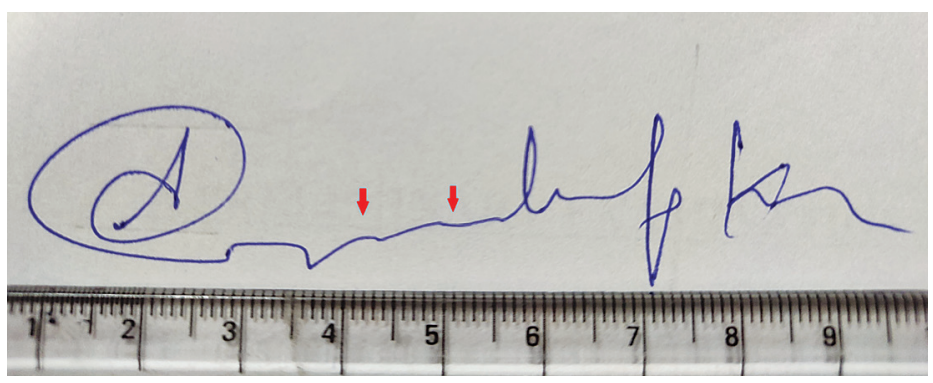

Figure 20a. The simplified letters in pen-paper signature

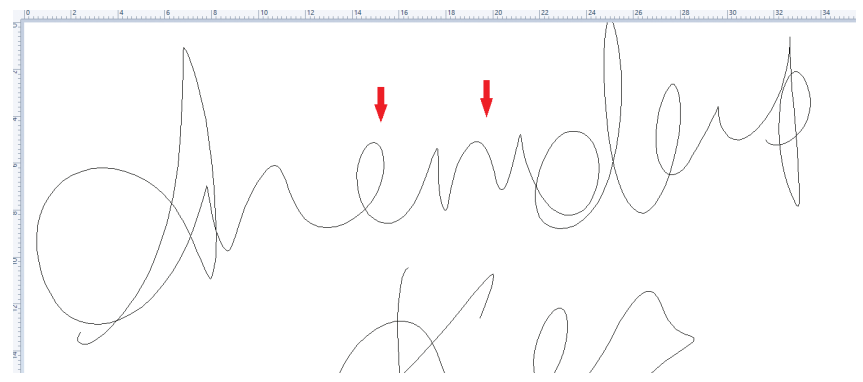

Figure 20b. The omission of simplification in pen-paper signature

\subsection{Forms and formation of letters}

It was observed that, despite differences in some letter forms, the direction of the stroke formation was the same. As evident from Figure 21a-b, Figure $22 \mathrm{a}-\mathrm{b}$, and Figure $23 \mathrm{a}-\mathrm{b}$, variations in the letter forms were found, such as eyelets instead of retracing, distorted letter forms, open ovals instead of closed ovals, but the direction of their formation remained the same. The differences in the letter forms were not remarkable enough to establish different authorship of the signature - they were found within the range of variation.

Harrison ${ }^{21}$ mentioned that there may be considerable variation in the shapes of letters, since a writer may use various forms of one letter. But the range of variation is a highly individual characteristic of each writer.

21 W.R. Harrison, Suspect documents: Their scientific examination, London 1958. 
The differences in letter forms beyond the range of variation could be due to the lack of visual feedback in tablet signatures, which leads to distorted letter forms or the presence of retracing instead of eyelets or loops. But the letter formation of electronic signatures and pen-paper signatures was found to be similar in all the samples.

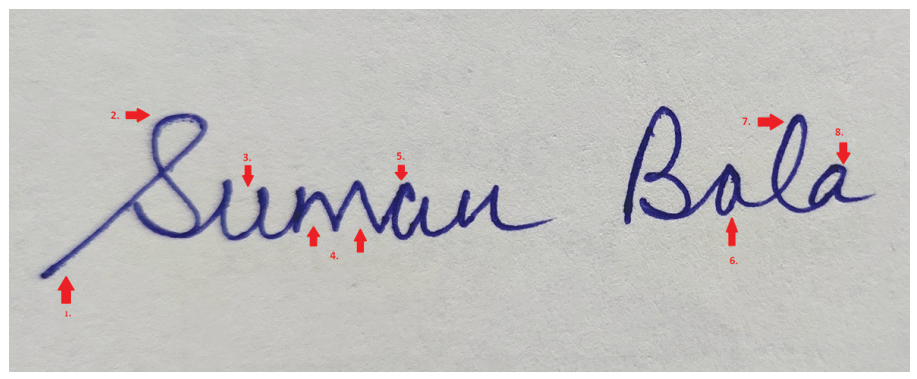

Figure 21a. Letter forms and formation in pen-paper signature

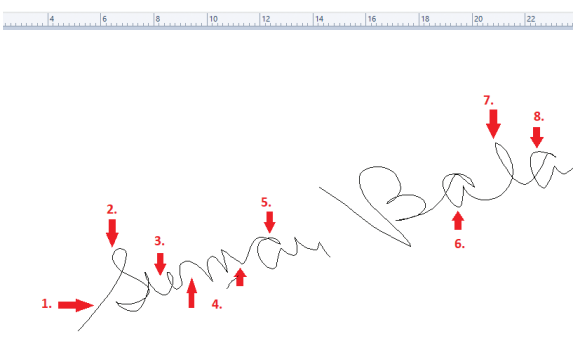

Figure 21b. The electronic signature

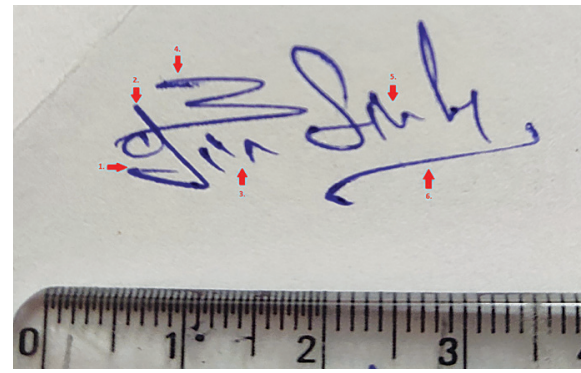

Figure 22a. Letter forms and formation in pen-paper signature 


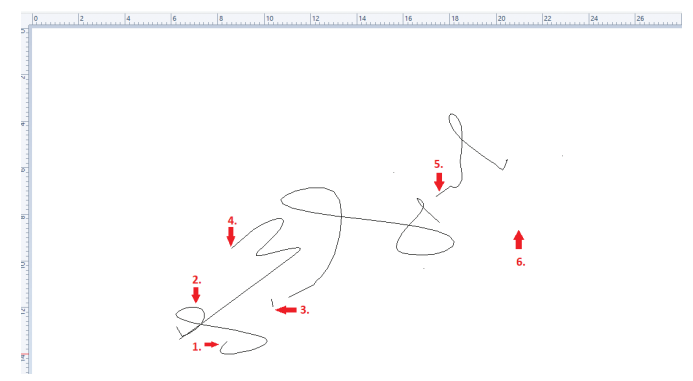

Figure $22 \mathrm{~b}$. The electronic signature

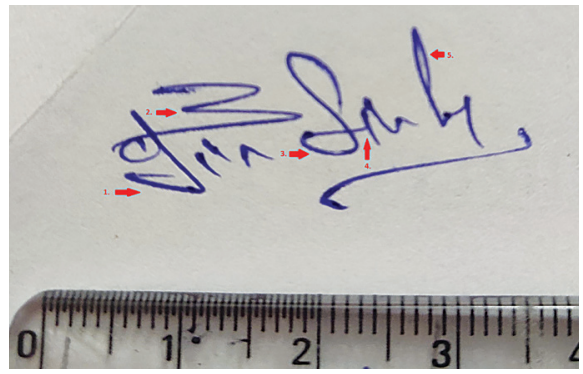

Figure 23a. Letter forms and formation in pen-paper signature

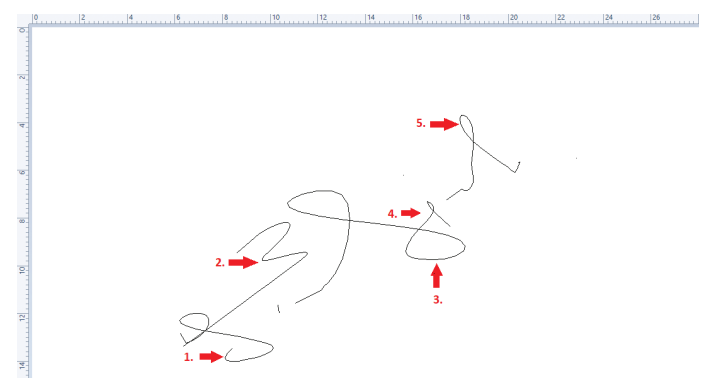

Figure 23b. The electronic signature 
Table 2a. A comparison of forms and formations in pen-paper and electronic signatures

\begin{tabular}{|l|l|l|l|}
\hline $\begin{array}{c}\text { Feature } \\
\text { no. }\end{array}$ & \multicolumn{1}{|c|}{ Feature } & \multicolumn{1}{|c|}{ Pen-paper signature } & \multicolumn{1}{|c|}{ Electronic signature } \\
\hline 1. & Initial stroke & $\begin{array}{l}\text { Starts from left down- } \\
\text { ward to right upward }\end{array}$ & $\begin{array}{l}\text { Starts from left down- } \\
\text { ward to right upward }\end{array}$ \\
\hline 2. & Crest & Present (anticlockwise) & Present (anticlockwise) \\
\hline 3. & Trough & Present (anticlockwise) & Present (anticlockwise) \\
\hline 4. & Arches & Present (clockwise) & Present (clockwise) \\
\hline 5. & Oval & Closed (anticlockwise) & Open (anticlockwise) \\
\hline 6. & Oval & Closed (anticlockwise) & Open (anticlockwise) \\
\hline 7. & Eyelet & Present (anticlockwise) & Present (anticlockwise) \\
\hline 8. & Connected stroke & $\begin{array}{l}\text { Retrace (downward to } \\
\text { upward) }\end{array}$ & $\begin{array}{l}\text { Eyelet (downward to } \\
\text { upward) }\end{array}$ \\
\hline
\end{tabular}

Table $2 b$. Similarities between features of pen-paper and electronic signatures

\begin{tabular}{|l|l|l|l|}
\hline $\begin{array}{c}\text { Feature } \\
\text { no. }\end{array}$ & \multicolumn{1}{|c|}{ Feature } & \multicolumn{1}{|c|}{ Pen-paper signature } & \multicolumn{1}{|c|}{ Electronic signature } \\
\hline 1. & Hook & Present (anticlockwise) & Present (anticlockwise) \\
\hline 2. & Compound curve & $\begin{array}{l}\text { Present (clockwise } \\
\text { to anticlockwise) }\end{array}$ & $\begin{array}{l}\text { Present (clockwise } \\
\text { to anticlockwise) }\end{array}$ \\
\hline 3. & Eyelet & Present (anticlockwise) & Present (anticlockwise) \\
\hline 4. & $\begin{array}{l}\text { Connecting } \\
\text { stroke }\end{array}$ & Present & Present \\
\hline 5. & Eyelet & Present (anticlockwise) & Present (anticlockwise) \\
\hline
\end{tabular}


Table 3a. Differences between features of pen-paper and electronic signatures

\begin{tabular}{|l|l|l|l|}
\hline $\begin{array}{c}\text { Feature } \\
\text { no. }\end{array}$ & \multicolumn{1}{|c|}{ Feature } & \multicolumn{1}{|c|}{ Pen-paper signature } & \multicolumn{1}{|c|}{ Electronic signature } \\
\hline 1. & Stroke endings & Tapered ends & Blunt ended \\
\hline 2. & Retracing & Present & Absent (Eyelet) \\
\hline 3. & $\begin{array}{l}\text { Omission } \\
\text { of strokes }\end{array}$ & Absent & Present \\
\hline 4. & Hook & Present & Absent \\
\hline 5. & Simplification & Absent & Present \\
\hline 6. & $\begin{array}{l}\text { Omission } \\
\text { of strokes }\end{array}$ & Absent & Present \\
\hline 7. & Rubric & Present & Absent \\
\hline
\end{tabular}

Table $3 \mathrm{~b}$. Similarities between features of pen-paper and electronic signatures

\begin{tabular}{|l|l|l|l|}
\hline $\begin{array}{c}\text { Feature } \\
\text { no. }\end{array}$ & \multicolumn{1}{|c|}{ Feature } & \multicolumn{1}{|c|}{ Pen-paper signature } & \multicolumn{1}{|c|}{ Electronic signature } \\
\hline 1. & Hook & Present (anticlockwise) & Present (anticlockwise) \\
\hline 2. & Compound curve & $\begin{array}{l}\text { Present (clockwise } \\
\text { to anticlockwise) }\end{array}$ & $\begin{array}{l}\text { Present (clockwise } \\
\text { to anticlockwise) }\end{array}$ \\
\hline 3. & Eyelet & Present (anticlockwise) & Present (anticlockwise) \\
\hline 4. & $\begin{array}{l}\text { Connecting } \\
\text { stroke }\end{array}$ & Present & Present \\
\hline 5. & Eyelet & Present (anticlockwise) & Present (anticlockwise) \\
\hline
\end{tabular}


Table 4. Occurence percentage of various features in electronic signatures

\begin{tabular}{|c|c|c|}
\hline $\begin{array}{c}\text { Feature } \\
\text { no. }\end{array}$ & Feature observed & $\begin{array}{l}\text { Occurrence of fea- } \\
\text { tures in electronic } \\
\text { signatures }\end{array}$ \\
\hline 1. & Increase in horizontal dimension & $100 \%$ \\
\hline 2. & Increase in vertical dimension & $100 \%$ \\
\hline 3. & Increase in spacing between letters & $80 \%$ \\
\hline 4. & Decrease in spacing between letters & $8 \%$ \\
\hline 5. & Increase in spacing between words & $38 \%$ \\
\hline 6. & Decrease in spacing between words & $6 \%$ \\
\hline 7. & Alignment change & $58 \%$ \\
\hline 8. & Arrangement change & $22 \%$ \\
\hline 9. & Omission of initial stroke & $18 \%$ \\
\hline 10. & Omission of terminal stroke & $10 \%$ \\
\hline 11. & Modification of initial stroke & $14 \%$ \\
\hline 12. & Modification of terminal stroke & $6 \%$ \\
\hline 13. & Extension of terminal stroke & $36 \%$ \\
\hline 14. & Addition of connecting stroke & $18 \%$ \\
\hline 15. & Modification of connecting stroke & $68 \%$ \\
\hline 16. & Extension of connecting stroke & $74 \%$ \\
\hline 17. & Addition of pen lifts & $42 \%$ \\
\hline 18. & Omission of pen lifts & $38 \%$ \\
\hline 19. & Omission of i-dots & $22 \%$ \\
\hline 20. & Modification of i-dot & $26 \%$ \\
\hline
\end{tabular}




\begin{tabular}{|l|l|c|}
\hline 21. & Change in position of i-dot & $20 \%$ \\
\hline 22. & Omission of t-cross & $4 \%$ \\
\hline 23. & Extension of t-cross & $12 \%$ \\
\hline 24. & Omission of embellishments & $18 \%$ \\
\hline 25. & Addition of embellishments & $16 \%$ \\
\hline 26. & Omission of rubrics & $4 \%$ \\
\hline 27. & Addition of rubrics & $4 \%$ \\
\hline 28. & Modification of rubrics & $22 \%$ \\
\hline 29. & Modification of embellishments & $72 \%$ \\
\hline 30. & Tremor & $18 \%$ \\
\hline 31. & Addition of simplification & $6 \%$ \\
\hline 32. & Omission of simplification & $70 \%$ \\
\hline 33. & Change in forms & $0 \%$ \\
\hline 34. & Change in formations & $100 \%$ \\
\hline 35. & Blunt stroke endings & \\
\hline
\end{tabular}

\section{Conclusions}

In the present study, the comparison of pen-paper signatures with electronic signatures was performed to identify the differences and similarities between them and find out if they are limited to the range of variation or amount to fundamental differences. The signature samples from 50 subjects were collected on paper and a digital pad. The features were selected for comparison between both signatures. Then the percentage of features occurring in electronic signatures was calculated.

The comparison between the paper and electronic signatures showed many differences in features, most common of which were changes in the vertical and horizontal dimension and blunt stroke endings. According to the observations made, it was due to the inability of subjects to adapt to a new device as well as its limitations, which caused differences in 
the features. The improper positioning of the stylus by the subjects led to pen lifts at unusual places and caused them to lose parts of the signatures, which may limit the examination of certain signature features. The prolonged touching of stylus on the surface of the electronic pad caused the addition of connecting strokes and extension of terminal strokes. Some samples lacked simplified forms of signature, which depicts that the writer might be more self-conscious while signing on a digital tablet. A tremor in strokes also appeared, which could be due to the lack of paper-like smoothness on the tablet surface. There were modifications in letter forms (such as retraces converted into eyelets), but the way of creating the forms (i.e. direction of formation) remained unchanged. In electronic signatures, unnatural pen lifts, abrupt change in direction, slow movement, a lack of tapered endings, and presence of tremulous strokes were observed, but these features should not be confused with the sign of forgery. The differences may mislead the examiners in terms of differentiating genuine signatures from forged signatures, but they were quite obviously caused by the device itself the writers' inability to adapt to it. The observed differences were almost the same in all the subjects and were not significant differences - letter formation, which is a very important feature for establishing the authorship, was found to be similar in both pen-paper and electronic signatures. It was concluded that despite differences, one can still establish the authorship from the comparison of electronic and pen-paper signatures.

\section{References}

Balint T., Bucko J., "Comparative analysis of handwritten, biometric and digital signature”, International Review of Social Sciences and Humanities 4, 2013.

Bharvada K., "Electronic signatures, biometrics and PKI in the UK", International Review of Law, Computers \& Technology 16, 2002.

Black H.C., Black's law dictionary, St. Paul, MN 2016, p. 123.

Doroz R., Porwik P., Orczyk T., "Dynamic signature verification method based on association of features with similarity measures", Neurocomputing 171, 2016.

Flynn J.W., Handwriting and signature examinations (a report), Affiliated Forensic Science Laboratories, Inc., https://topazsystems.com/ (accessed: 9.11.2016).

Galen G., Gemmert A. van, “Kinematic and dynamic features of forging another person's handwriting", Journal of Forensic Document Examination 9, 1996, pp. 1-25. 
Harralson H.H., Developments in handwriting and signature identification in the digital age, Oxford 2013

Harralson H.H., Teulings H.L., Miller S.L., "Temporal and spatial differences between online and offline signatures", 15th International Graphonomics Society Conference, 12-15 June 2011, Cancún.

Harrison W.R., Suspect documents: Their scientific examination, London 1958.

Hilton O., The scientific examination of questioned document, New York 1982.

Huber R.A., Headrick A.M., Handwriting identification: Facts and fundamentals, Boca Raton, FL 1999.

Jasuja O.P. et al., "Spray paint writings on vertical surfaces executed by spray paint cans: A preliminary forensic study", Z Zagadnień Nauk Sadowych (Problems of Forensic Sciences) 98, 2014.

Kaźmierczyk Z., Turner I., "Is your electronic signature really yours?", https://www.acade mia.edu/6630002/Is_your_electronic_signature_really_yours (accessed: 18.11.2016).

Kelly J.S., Lindblom B.S., Scientific examination of documents, New York 2006.

Koppenhaver K.M., Forensic document examination: Principles and practice, Totowa, NJ 2007.

Lei H., GovindarajuV., "A comparative study on the consistency of features in online signature verification", Pattern Recognition Letters 26, 2005.

Liwicki M., "Automatic signature verification: In-depth investigation of novel features and different models", Journal of Forensic Document Examination 22, 2012.

Mason S., "Electronic signatures - Evidence: The evidential issues relating to electronic signatures", part 1 and part 2, Computer Law \& Security Report 18, 2002, no. 3, pp. $175-180$, no. 4.

Mason S., "A comparison of the risks between the use of manuscript and electronic signatures", Amicus Curiae 50, 2003.

Mehta M.K, Identification of handwriting and cross examination of experts, Bombay 1970.

Mohammed L.et al., "Dynamic characteristics of signatures: Effects of writer style on genuine and simulated signatures", Journal of Forensic Sciences 60, 2015, no.1.

Osborn A.S., Questioned documents, Albany, NY 1929.

Plamondon R., Srihari S.N., "On-line and off-line handwriting recognition: A comprehensive survey", IEEE Transactions on Pattern Analysis and Machine Intelligence 22, 2000.

Richiardi J., Ketabdar H., Drygajlo A., "Local and global feature selection for online signature verification", International conference on document analysis and recognition, 29 August-1 September 2005.

Tariq S., Sarwar S., Hussain W., "Classification of features into strong and weak features for an intelligent online signature verification system", Proceedings of the 1st International Workshop on Automated Forensic Handwriting Analysis (AFHA), 17-18 September 2011, Bejing.

Tolosana R. et al., "Feature-based dynamic signature verification under forensic scenarios", 3rd International Workshop on Biometrics and Forensics (IWBF), Gjovik 2015.

Wright B., "Making electronic signatures a reality", Computer Law \& Security Review 15, 199, no. 6, pp. 401-402.

Nowa Kodyfikacja Prawa Karnego 59, 2021

(C) for this edition by CNS 